\title{
Neuroendocrine Cancer, Therapeutic Strategies in G3 Cancers
}

\author{
Anja Rinke Thomas M. Gress \\ Department of Gastroenterology, University Hospital Marburg, Marburg, Germany
}

\section{Keywords}

Neuroendocrine neoplasm - Neuroendocrine carcinoma ·

Neuroendocrine tumour · Grading · Proliferation

marker Ki67 · Treatment · Chemotherapy

\begin{abstract}
Background: According to the latest WHO classification, neuroendocrine neoplasm (NEN) G3 of the gastrointestinal tract is defined by a proliferation index Ki67 above 20\%. Gastrointestinal neuroendocrine carcinoma (NEC) is a rare and highly aggressive malignancy and despite responsiveness to chemotherapy, overall survival is poor. In the last 3-4 years, the heterogeneity of the NEN G3 group has become evident. Summary: In addition to the proliferative activity, the tumour differentiation seems to play a major role, further dividing the NEN G3 group into neuroendocrine tumour (NET) G3 and NEC. NET G3 often arise in the pancreas, and their median proliferation rate is lower and prognosis is better as compared to NEC. However, NET G3 show a limited response to platinum-based chemotherapy. Lack of specific data for NET G3 hampers clear therapeutic recommendations. Cisplatin combined with etoposide is the established standard regimen for advanced gastrointestinal NEC. Substituting carboplatin for cisplatin or irinotecan for etoposide is considered alternative first-line regimen. There is no standard second-line treatment; options are discussed within this review.
\end{abstract}

Key Points: (1) In NEN G3, the distinction between NET G3 and NEC G3 is clinically and prognostically meaningful. (2) Platinum-based chemotherapy remains the recommended first-line treatment in metastasized NEC patients. (3) There is no established standard for NET G3; treatments established for NET G2 such as temozolomide-based chemotherapy or peptide receptor radiotherapy may be considered. (4) Specific trials for NET G3 are necessary. (5) New therapies for NEC are urgently needed. Checkpoint inhibitors should be evaluated.

(c) 2017 S. Karger AG, Basel

\section{Introduction: Pathological, Clinical and Prognostic Heterogeneity of Neuroendocrine Neoplasm G3}

According to the WHO classification of gastrointestinal neuroendocrine neoplasm (NEN) 2010, high-grade $\mathrm{NEN}$ are defined by a proliferative index of Ki67 exceeding $20 \%$ and/or mitotic count above 20 mitoses in 10 high-power fields [1]. Only about $5 \%$ of all gastrointestinal NEN belong to the G3 category [2]; thus, only limited data exists on appropriate treatment strategies for this rare disease. Until recently, NEN G3 has been regarded to be equivalent to poorly differentiated neuroendocrine carcinoma (NEC) and therefore, patients with NEN G3 have been uniformly treated with platinum-

\section{KARGER}

(c) 2017 S. Karger AG, Basel

E-Mail karger@karger.com

www.karger.com/dig
Anja Rinke

Department of Gastroenterology and Endocrinology University Hospital Marburg

Baldinger Strasse, DE-35043 Marburg (Germany)

E-Mail sprengea@staff.uni-marburg.de 
based chemotherapy. The largest retrospective study on gastrointestinal NEN G3 - the so-called Nordic NEC trial - reported a lower response rate (RR) to platinumbased chemotherapy in patients with Ki67 <55\% (15\%) compared to patients with high proliferative activity exceeding Ki67 55\% (42\%; $p<0.01)$. Nevertheless, overall prognosis was superior in the subgroup of patients with Ki67 <55\% [3].

Some recent publications stressed the importance of morphological differentiation and suggested that the NEN G3 group should be stratified into morphologically well-differentiated neuroendocrine tumours (NET) with an elevated proliferation rate (NET G3) and into poorly differentiated NEC of large and small cell types [4-6]. Although prognosis in patients with NET G3 was slightly worse compared to that in patients with NET G2 [6], it was clearly more favourable when compared to NEC. For the NET G3 subgroup, a median overall survival of 54-99 months was reported contrasting to 11-17 months for the NEC subgroup [5-7]. NET G3 were more often somatostatin receptor positive (about $90 \%$ of cases versus $40-50 \%$ of cases in NEC), and the primary tumour was often located in the pancreas (about two thirds of cases). Functional activity is uncommon in the whole G3 group but still found more often in patients with NET G3 (5-41\%) as compared to NEC patients (0-6\%) [4-6]. Response to platinum-based treatment was inferior in NET G3 patients with an objective RR between 0 and $17 \%$ as compared to $31-35 \%$ in NEC patients in these series $[4,5]$. Some studies reported a younger age at diagnosis for patients with NET G3 as compared to patients with NEC [5]. Although the proliferation rate was usually lower in NET G3 (median 30-50\%) than that in NEC (median $70-80 \%$ ) and a Ki67 index above 55\% was rarely documented in NET G3, no clear cut-off value that distinguishes NET from NEC could be defined [7]. Therefore, even the subgroup of NEC may be heterogeneous with a very aggressive subtype resembling small cell lung cancer (SCLC; "NEC G4") and a lower proliferative NEC ("NEC G3") with potential therapeutic implications.

The concept of at least 2 different neoplasms within the group of NEN G3 is supported by recent genetic analyses: the typical mutations of well-differentiated pancreatic NET such as DAXX/ATRX mutations [8] are found in about half of the pancreatic NET G3 cases but not in pancreatic NEC, whereas large and small cell NEC of the pancreas often display the inactivation of the TP53 and the Rb/p16 pathways that are not found in NET $[7,9]$.

\section{First-Line Treatment in NEC}

Evidence for treatment recommendations in gastrointestinal NEC is limited to mainly retrospective series and a few non-controlled small trials. Patients are often treated in analogy to the more common SCLC.

For 25 years, cytotoxic treatment with cisplatin and etoposide has been used as standard treatment for metastatic NEC [10]. Moertel and colleagues described an overall remission rate of $67 \%$ (which may be an overestimate compared to objective RRs based on actual radiologic criteria such as RECIST) and a median survival of 19 months. Response to treatment was independent of primary tumour localization. Mitry et al. [11] reported comparable results with an RR of $42 \%$ and a median survival of 15 months using a modified cisplatin and etoposide regimen in a cohort of 41 patients.

In SCLC, substitution of carboplatin for cisplatin was not inferior and better tolerated with regard to gastrointestinal and renal toxicity [12]. For extrapulmonal NECs, 2 small studies with carboplatin etoposide reported a median survival of 20 and 12.7 months respectively [13]. Further support for the equal efficacy of carboplatin compared to cisplatin originates from the Nordic NEC trial: median survival was similar in patients treated with firstline cisplatin and etoposide (12 months) and carboplatin and etoposide (11 months) [3]. The combination of irinotecan and cisplatin may be an alternative. A large Japanese retrospective study reported higher RRs and survival for this combination compared to cisplatin and etoposide (RR 50 vs. $28 \%$ and survival 13 vs. 7 months). However, in this study, unequal allocation of patients to the 2 treatment groups may have influenced these observations, since location of the primary and elevated levels of lactate dehydrogenase were independent prognostic factors for overall survival, whereas the treatment schedule was not [14].

Adding a third drug such as paclitaxel [15] or vincristin [3] to platinum plus etoposide did not result in a survival advantage.

Although a subgroup of NEC patients expresses somatostatin receptors, there is no indication to use somatostatin analogues for tumour control in NEC. In addition, highly proliferative NEC patients usually do not benefit from somatostatin receptor-based peptide receptor radiotherapy (PRRT) [2].

Surgery often is the first-line treatment in localized disease, but cure by surgery alone is rare. Therefore, most oncologists would recommend platinum-based adjuvant treatment, although data supporting this concept 
Table 1. Second- and third-line treatments in NEC

\begin{tabular}{|c|c|c|c|c|c|c|c|}
\hline Author, year & Entities/primaries & Schedule & $n$ & ORR, \% & DCR, \% & $\mathrm{mPFS}$ & mOS \\
\hline Welin et al. [19], 2011 & $\begin{array}{l}48 \% \leq 30 \% \text { Ki67 } \\
\text { GEP/UK/lung }\end{array}$ & $\begin{array}{l}\text { Temozolomide } \pm \\
\text { capecitabine } \pm \\
\text { bevacizumab }\end{array}$ & 25 & 33 & 71 & 6 & 22 \\
\hline Hentic et al. [17], 2012 & $\begin{array}{l}\text { GEP NEC } \\
\text { mKi67: } 50 \%\end{array}$ & FOLFIRI & 19 & 31 & 57 & 4 & 18 \\
\hline Sorbye et al. [3], 2013 & NEC GEP/UK & $\begin{array}{l}\text { Reintroduction } \\
\text { platin + etoposide }\end{array}$ & 26 & 15 & 27 & ns & $\begin{array}{l}19 \text { from initial } \\
\text { treatment }\end{array}$ \\
\hline Olsen et al. [16], 2014 & $\begin{array}{l}\text { NEC GEP/UK } \\
\text { mKi67: 95\% }\end{array}$ & Topotecan & 22 & 0 & 23 & 2.1 & 3.2 \\
\hline
\end{tabular}

ORR, objective response rate; $\mathrm{DCR}$, disease control rate; $\mathrm{mPFS}$, median progression free survival; $\mathrm{mOS}$, median overall survival; GEP, gastroenteropancreatic; UK, unknown; Cap, capecitabine; Bev, bevacizumab; NEC, neuroendocrine carcinoma; GU, genitourinary; ns, not stated; SC, small cell; LC, large cell.

are scarce. After curatively intended surgery, prophylactic cranial irradiation is not recommended, since brain metastases are much rarer than in patients with SCLC [2, $3]$.

\section{Second- and Third-Line Treatment Options in NEC}

In patients demonstrating progressive disease after platinum-based, first-line chemotherapy, no standard treatment is available.

The limited data for second-line options from small retrospective series are summarized in Table 1. In contrast to SCLC, topotecan did not induce any remissions and resulted in a poor median PFS of only 2.1 months in a small series of gastrointestinal NECs [16]. We therefore do not recommend this drug for second-line treatment in gastrointestinal NEC.

The most commonly used options comprise: (i) the reintroduction of platinum and etoposide when a durable response is achieved in the first line and when progression occurs more than 3 months after the end of first-line treatment, (ii) irinotecan-based treatment (FOLFIRI) [17], and (iii) oxaliplatin-based treatments (FOLFOX or XELOX) [2, 18]. The Uppsala group suggested the use of temozolomide alone or in combination with capecitabine and/or bevacizumab as second-line treatment [19]. Patients with $\mathrm{Ki} 67<60 \%$ and positive somatostatin receptor scintigraphy responded more often, probably corresponding at least in part to patients with NET G3 rather than NEC. Another small retrospective study in NEC patients failed to demonstrate the efficacy of temozolomide [20].

\section{Treatment Strategies in Neuroendocrine Tumors G3}

As the WHO classification 2010 did not define a G3 subgroup with retained differentiation, there are no specific treatment data available for this subgroup. Because of the lower RRs to platinum-based chemotherapy observed in several retrospective trials [3-5] and the fact that biology and prognosis of NET G3 are closer to NET G2 than to NEC (see Introduction), considering treatment options established for progressive NET G2 seems appropriate. According to the ENETS guidelines [2, 21], therapeutic alternatives comprise temozolomide-based chemotherapy and - in case of a pancreatic primary (two thirds of cases) - streptozocin-based chemotherapy. PRRT can also be successful in receptor-positive cases, although generally RR and duration of response in G3 are lower when compared to G1/2 NET [22]. The possible activity of everolimus and sunitinib for NET G3 needs further investigation. For the extremely rare differentiated NET G3 with high proliferative activity exceeding Ki67 55\%, most clinicians will probably still de- 


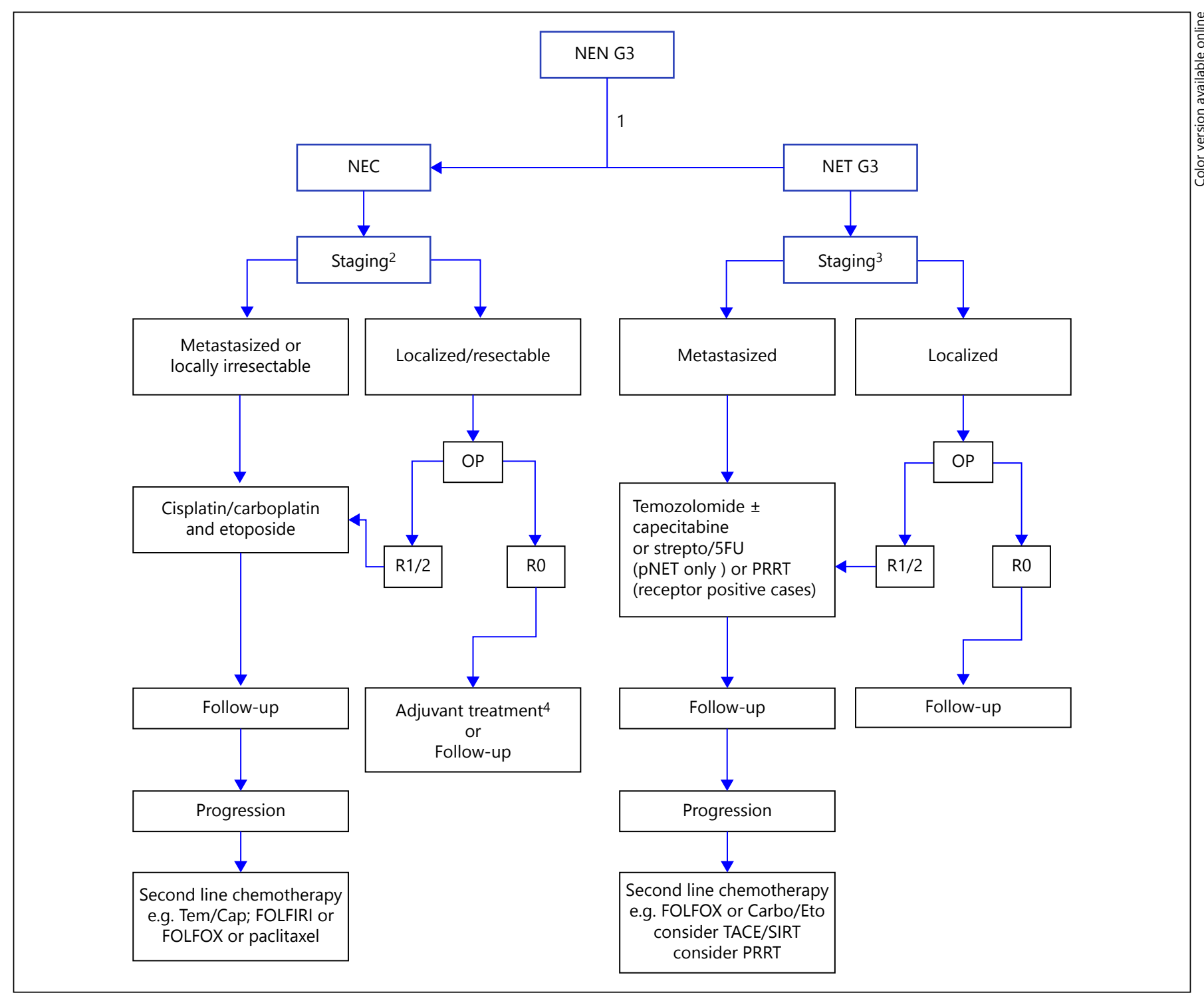

Fig. 1. Diagnostic and therapeutic algorithm in patients with gastroenteropancreatic NEN G3. ${ }^{1}$ If Ki67 $\leq 55 \%$, always consult a pathologist: NET G3 or NEC? In doubtful cases, reference pathology is recommended. ${ }^{2}$ Staging includes CT of chest and abdomen (or FDG-PET-CT), bone scintigraphy, MRI of the brain, tumour marker neurone specific enolase (NSE), hormone markers only if clinically suspected syndrome. ${ }^{3}$ Staging includes CT of the chest, $\mathrm{CT}$ or MRI of the abdomen, somatostatin receptor imaging (preferentially ${ }^{68} \mathrm{Ga}$-DOTATOC-PET-CT), chromogranin A, if negative: NSE, hormone markers only if clinically suspected syndrome.

cide to use a platinum-based chemotherapy as first-line treatment.

A randomized phase II trial comparing temozolomide + capecitabine with cisplatin + etoposide (EA2142) as first-line treatment in NEN G3 excluding small cell
${ }^{4}$ Adjuvant treatment: 4 cycles of cisplatin + etoposide \pm radiatio. NEN, neuroendocrine neoplasm; NEC, neuroendocrine carcinoma; NET, neuroendocrine tumour; OP, operation; Strepto/5FU, chemotherapy with streptozocin and 5 fluorouracil; pNET, pancreatic neuroendocrine tumour; PRRT, peptide receptor radiotherapy; Tem/Cap, chemotherapy with temozolomide and capecitabine; Carbo/Eto, chemotherapy with carboplatin and etoposide; TACE, transarterial chemoembolization; SIRT, selective internal radiotherapy.

NEC will provide further information on the best treatment choice.

Our treatment strategy in patients with NEN G3 is summarized in Figure 1. 


\section{Perspectives}

A better characterization of the heterogeneous NEN G3 group and specific therapeutic trials for subgroups is urgently needed.

The Scandinavian group started a phase II trial for first-line treatment using a combination of temozolomide and everolimus (NCT02248012) in patients with NEN G3 Ki67 <55\%.

New treatment options in NEC patients whose prognosis has remained dismal for the last decades are urgently needed. Checkpoint inhibitors, such as nivolumab or pembrolizumab, represent fascinating new compounds that need to be studied in NEN G3. Kim et al. [23] have, for example, shown that PD-L1 expression in NEN is associated with G3 grading and poor prognosis. In Merkel cell carcinoma, which also represents a high-grade neuroendocrine cancer, pembrolizumab as first-line treatment resulted in an objective RR of $56 \%$ [24]. In $12 \%$ of gastric and colonic NEC, a mismatch repair deficiency was found - a condition associated with response to checkpoint inhibitors in colon cancer. Thus, rationale exists to further investigate immunotherapy in NEN G3 and to identify patients who could benefit from these novel treatment options.

Another approach is the evaluation of new targeted treatments. For example, an increased expression of the protein delta-like 3 (DLL3) was discovered in highgrade pulmonary NEC [25], and a DLL3-targeted antibody-drug conjugate will be evaluated in several DLL3 expressing malignancies, including gastrointestinal NEC.

\section{Key Points}

1. Within the group of NEN G3, the distinction between NET G3 and NEC G3 is clinically and prognostically meaningful.

2. Chemotherapy with cis- or carboplatin combined with etoposide remains the recommended first-line treatment in metastasized NEC patients.

3. There is no established standard for NET G3; treatments established for NET G2 such as temozolomidebased chemotherapy or PRRT may be considered.

4. Specific trials for NET G3 are necessary.

5. New therapeutic options for NEC are urgently needed. Checkpoint inhibitors should be evaluated.

\section{Disclosure Statement}

The authors declare that they have no potential conflicts of interest to disclose related to this review.

\section{References}

1 Rindi G, Arnold R, Bosman FT, Capella C, Klimstra DS, Klöppel G, Komminoth P: Nomenclature and classification of neuroendocrine neoplasms of the digestive system; in Bosman FT, Carneiro F, Hruban RH, Theise ND (eds): WHO Classification of Tumors of the Digestive System. Lyon, IARC, 2010, pp S13-S14.

2 Garcia-Carbonero R, Sorbye H, Baudin E, Raymond E, Wiedenmann B, Niederle B, Sedlackova E, Toumpanakis C, Anlauf M, Cwikla JB, Caplin M, O’Toole D, Perren A; Vienna Consensus Conference Participants: ENETS consensus guidelines for high-grade gastroenteropancreatic neuroendocrine tumors and neuroendocrine carcinomas. Neuroendocrinology 2016;103:186-194.

3 Sorbye H, Welin S, Langer SW, Vestermark LW, Holt N, Osterlund P, Dueland S, Hofsli E, Guren MG, Ohrling K, Birkemeyer E, Thiis-Evensen E, Biagini M, Gronbaek H, Soveri LM, Olsen IH, Federspiel B, Assmus J, Janson ET, Knigge U: Predictive and prognostic factors for treatment and survival in 305 patients with advanced gastrointestinal neuroendo- crine carcinoma (WHO G3): the NORDIC NEC study. Ann Oncol 2013;24:152-160.

4 Vélayoudom-Céphise FL, Duvillard P, Foucan L, Hadoux J, Chougnet CN, Leboulleux S, Malka D, Guigay J, Goere D, Debaere T, Caramella C, Schlumberger M, Planchard D, Elias D, Ducreux M, Scoazec JY, Baudin E: Are G3 ENETS neuroendocrine neoplasms heterogeneous? Endocr Relat Cancer 2013;20:649-657.

5 Heetfeld M, Chougnet CN, Olsen IH, Rinke A, Borbath I, Crespo G, Barriuso J, Pavel M, O'Toole D, Walter T; Other Knowledge Network Members: Characteristics and treatment of patients with G3 gastroenteropancreatic neuroendocrine neoplasms. Endocr Relat Cancer 2015;22:657-664.

6 Basturk O, Yang Z, Tang LH, Hruban RH, Adsay V, McCall CM, Krasinskas AM, Jang KT, Frankel WL, Balci S, Sigel C, Klimstra DS: The high-grade (WHO G3) pancreatic neuroendocrine tumor category is morphologically and biologically heterogenous and includes both well differentiated and poorly differentiated neoplasms. Am J Surg Pathol 2015;39: 683-690.
7 Tang LH, Basturk O, Sue JJ, Klimstra DS: A practical approach to the classification of WHO grade 3 (G3) well-differentiated neuroendocrine tumor (WD-NET) and poorly differentiated neuroendocrine carcinoma (PD-NEC) of the pancreas. Am J Surg Pathol 2016;40:1192-1202.

8 Jiao Y, Shi C, Edil BH, de Wilde RF, Klimstra DS, Maitra A, Schulick RD, Tang LH, Wolfgang CL, Choti MA, Velculescu VE, Diaz LA Jr, Vogelstein B, Kinzler KW, Hruban RH, Papadopoulos N: DAXX/ATRX, MEN1, and mTOR pathway genes are frequently altered in pancreatic neuroendocrine tumors. Science 2011;331:1199-1203.

9 Yachida S, Vakiani E, White CM, Zhong Y, Saunders T, Morgan R, de Wilde RF, Maitra A, Hicks J, Demarzo AM, Shi C, Sharma R, Laheru D, Edil BH, Wolfgang CL, Schulick RD, Hruban RH, Tang LH, Klimstra DS, Iacobuzio-Donahue CA: Small cell and large cell neuroendocrine carcinomas of the pancreas are genetically similar and distinct from well-differentiated pancreatic neuroendocrine tumors. Am J Surg Pathol 2012;36:173-184. 
10 Moertel CG, Kvols LK, O’Connell MJ, Rubin $\mathrm{J}$ : Treatment of neuroendocrine carcinomas with combined etoposide and cisplatin. Evidence of major therapeutic activity in the anaplastic variants of these neoplasms. Cancer 1991;68:227-232.

11 Mitry E, Baudin E, Ducreux M, Sabourin JC, Rufié P, Aparicio T, Aparicio T, Lasser P, Elias D, Duvillard P, Schlumberger M, Rougier $\mathrm{P}$ : Treatment of poorly differentiated neuroendocrine tumours with etoposide and cisplatin. Br J Cancer 1999;81:13511355.

12 Rossi A, Di Maio M, Chiodini P, Rudd RM, Okamoto H, Skarlos DV, Früh M, Qian W, Tamura T, Samantas E, Shibata T, Perrone F, Gallo C, Gridelli C, Martelli O, Lee SM: Carboplatin- or cisplatin-based chemotherapy in first-line treatment of small-cell lung cancer: the COCIS meta-analysis of individual patient data. J Clin Oncol 2012;30:16921698.

13 Imai H, Shirota H, Okita A, Komine K, Saijo K, Takahashi M, Takahashi S, Takahashi M, Shimodaira $\mathrm{H}$, Ishioka C: Efficacy and safety of carboplatin and etoposide combination chemotherapy for extrapulmonary neuroendocrine carcinoma: a retrospective case series. Chemotherapy 2016;61:111-116.

14 Yamaguchi T, Machida N, Morizane C, Kasuga A, Takahashi H, Sudo K, Nishina T, Tobimatsu K, Ishido K, Furuse J, Boku N, Okusaka T: Multicenter retrospective analysis of systemic chemotherapy for advanced neuroendocrine carcinoma of the digestive system. Cancer Sci 2014;105:1176-1181.

15 Hainsworth JD, Spigel DR, Litchy S, Greco FA: Phase II trial of paclitaxel, carboplatin, and etoposide in advanced poorly differentiated neuroendocrine carcinoma: a Minnie
Pearl Cancer Research Network Study. J Clin Oncol 2006;24:3548-3554.

16 Olsen IH, Knigge U, Federspiel B, Hansen CP, Skov A, Kjær A, Langer SW: Topotecan monotherapy in heavily pretreated patients with progressive advanced stage neuroendocrine carcinomas. J Cancer 2014;5:628-632.

17 Hentic O, Hammel P, Couvelard A, Rebours V, Zappa M, Palazzo M, Maire F, Goujon G, Gillet A, Lévy P, Ruszniewski P: FOLFIRI regimen: an effective second-line chemotherapy after failure of etoposide-platinum combination in patients with neuroendocrine carcinomas grade 3. Endocr Relat Cancer 2012;19: 751-757.

18 Hadoux J, Malka D, Planchard D, Scoazec JY, Caramella C, Guigay J, Boige V, Leboulleux S, Burtin P, Berdelou A, Loriot Y, Duvillard P, Chougnet CN, Déandréis D, Schlumberger M, Borget I, Ducreux M, Baudin E: Post-firstline FOLFOX chemotherapy for grade 3 neuroendocrine carcinoma. Endocr Relat Cancer 2015;22:289-298.

19 Welin S, Sorbye H, Sebjornsen S, Knappskog S, Busch C, Oberg K: Clinical effect of temozolomide-based chemotherapy in poorly differentiated endocrine carcinoma after progression on first-line chemotherapy. Cancer 2011;117:4617-4622.

20 Olsen IH, Sørensen JB, Federspiel B, Kjaer A, Hansen CP, Knigge U, Langer SW: Temozolomide as second or third line treatment of patients with neuroendocrine carcinomas. ScientificWorldJournal 2012;2012: 170496.

21 Pavel M, O’Toole D, Costa F, Capdevila J, Gross D, Kianmanesh R, Krenning E, Knigge U, Salazar R, Pape UF, Öberg K; Vienna Consensus Conference Participants: ENETS consensus guidelines update for the manage- ment of distant metastatic disease of intestinal, pancreatic, bronchial neuroendocrine neoplasms (NEN) and NEN of unknown primary site. Neuroendocrinology 2016;103:172-185.

22 Ezziddin S, Opitz M, Attassi M, Biermann K, Sabet A, Guhlke S, Brockmann H, Willinek W, Wardelmann E, Biersack HJ, Ahmadzadehfar H: Impact of the Ki-67 proliferation index on response to peptide receptor radionuclide therapy. Eur J Nucl Med Mol Imaging 2011;38:459-466.

23 Kim ST, Ha SY, Lee S, Ahn S, Lee J, Park SH, Park JO, Lim HY, Kang WK, Kim KM, Park YS: The impact of PD-L1 expression in patients with metastatic GEP-NETs. J Cancer 2016;7:484-489.

24 Nghiem PT, Bhatia S, Lipson EJ, Kudchadkar RR, Miller NJ, Annamalai L, Berry S, Chartash EK, Daud A, Fling SP, Friedlander PA, Kluger HM, Kohrt HE, Lundgren L, Margolin K, Mitchell A, Olencki T, Pardoll DM, Reddy SA, Shantha EM, Sharfman WH, Sharon E, Shemanski LR, Shinohara MM, Sunshine JC, Taube JM, Thompson JA, Townson SM, Yearley JH, Topalian SL, Cheever MA: PD-1 blockade with pembrolizumab in advanced Merkel-cell carcinoma. N Engl J Med 2016;374:2542-2552.

25 Saunders LR, Bankovich AJ, Anderson WC, Aujay MA, Bheddah S, Black K, Desai R, Escarpe PA, Hampl J, Laysang A, Liu D, LopezMolina J, Milton M, Park A, Pysz MA, Shao $\mathrm{H}$, Slingerland B, Torgov M, Williams SA, Foord O, Howard P, Jassem J, Badzio A, Czapiewski P, Harpole DH, Dowlati A, Massion PP, Travis WD, Pietanza MC, Poirier JT, Rudin CM, Stull RA, Dylla SJ: A DLL3targeted antibody-drug conjugate eradicates high-grade pulmonary neuroendocrine tumor-initiating cells in vivo. Sci Transl Med 2015;7:302ra136. 